\title{
LA INJURIA AL HONOR COMO MOTIVACIÓN DE GUERRA, SEGÚN VITORIA, MOLINA Y SUÁREZ
}

Juan Cruz Cruz*

RESUMO - Quando um grande pensador da Era de Ouro espanhola, tal qual Vitoria, Molina ou Suárez, questiona sobre a causa fundamental que justifica uma lícita declaração de guerra, a "injúria" é incluída como uma dessas causas. Aqui, "injúria" é entendida como uma infração de um direito, uma injustiça cometida e pela qual a reparação não foi feita. Dentre as injúrias que podem licitamente ser consideradas uma justificativa para a guerra, há o "insulto à honra", especialmente à honra da Nação e à honra do Soberano. A dificuldade em aceitar essa justificativa para a guerra reside em fazer uma separação entre o interesse do Soberano e o interesse do povo, i.e., os homens que compõem a comunidade, que são os depositários imediatos do poder. Para esses pensadores, a honra é sempre possuída pelo povo. E isso porque um Estado, uma Nação, um povo tem o direito de desfrutar o respeito por suas instituições, leis e costumes, tal qual uma parte integral de sua própria vida.

PALAVRAS-CHAVE: Injúria. Vitoria. Molina. Suárez. Guerra.
ABSTRACT - When a great thinker of the Spanish Golden Age, such as Vitoria, Molina or Suárez, inquires about the fundamental cause which justifies a licit declaration of war, "injury" is included as one of these causes. Here, "injury" is understood as an infringement of a right, an injustice committed and for which restitution has not been made. Among the injuries which may licitly be considered a justification for war, there is the "insult to honor", especially to the honor of the Nation and the honor of the Sovereign. The difficulty in accepting this justification for war lies in making a demarcation between the interest of the Sovereign and the interest of the People, i.e. the men who make up the community, who are the immediate depositaries of power. For these thinkers, honor is always owed to the People. This is because a State, a Nation, a People, has the right to enjoy respect for its institutions, laws and customs, as an integral part of its own life.

KEY WORDS - Injury. Vitoria. Molina. Suarez. War.

* Universidad de Navarra.

\begin{tabular}{|l|l|l|l|l|l|}
\hline VERITAS & Porto Alegre & v. 54 & n. 3 & set./dez. 2009 & p. 13-33 \\
\hline
\end{tabular}




\section{La iniuria como título general o motivo de guerra}

1. Entre las razones suficientes que inducen a emprender acciones bélicas hay una, la injuria al honor, ya señalada hace 25 siglos por Tucídides, entre otras dos: "el honor, el temor y el interés".

$\mathrm{Y}$ bajo la tesis de que el honor ha sido una causa importante de las guerras ha escrito recientemente Donald Kagan un libro Sobre las causas de la guerra y la preservación de la paz. ${ }^{1}$ Para probarlo repasa los momentos anteriores a la Guerra del Peloponeso (431-404 a. de C.), a la Primera Guerra Mundial (1914-1918), a la Segunda Guerra Púnica (218202 a.C.), a la Segunda Guerra Mundial (1939-1945) y a la Crisis de los Misiles en Cuba (1962). No describe el desarrollo de cada contienda, sino los actos anteriores al desenlace bélico, las relaciones diplomáticas y las deliberaciones previas de los gobiernos de cada país. Kagan concluye que la lucha - propiciada por los antagonismos - busca fundamentalmente el poder. Pero no siempre la búsqueda del poder tiene su aguijón en el miedo o en la consecución de la seguridad o de ventajas materiales, porque hay otra razón igualmente desencadenante: "un prestigio mayor, respeto, deferencia, en resumen, honor". ${ }^{2}$

2. Aunque de la obra de Vitoria se sigue claramente la doctrina de que la "gloria" del príncipe, su "fama" o su "honor" pueden ser puestos en balanza para justificar la guerra misma; sin embargo el maestro dominico no elaboró explícitamente este punto. Lo harían Molina y Suárez. Lo decisivo para Vitoria es la iniuria, la violación clara de un derecho.

En realidad, cuando un Maestro del Siglo de Oro se pregunta por los títulos de guerra - o la causa fundamental para declarar lícitamente la guerra - señala inmediatamente la iniuria, la violación de un derecho - una injusticia hecha y no reparada. ${ }^{3}$ Es lo que sustancialmente había enseñado ya San Agustín, ${ }^{4}$ el referente intelectual más alto que, con

Cfr. KAGAN, D. 2003.

KAGAN. op. cit., p. 494.

FRANCISCO de Vitoria. De Indis posterior, sive De iure belli, n. 1 y n. 13.

4 San Agustín habla de la guerra en Contra Faustum, lib. XXII, c. 74-78. (ML, 42, 447 y s.s.), De libero arbitrio lib. 1, cap. V (ML, 32, 1.227), Quaestiones in Hept., lib. IV y VI. (ML, 34, 717 y ss.), De Civitate Dei, lib. XIX, cap. VII, XII, XIII y XV (ML, 41, 633 y ss.). Para San Agustín la guerra puede ser justa si trata de rechazar las acciones perversas del adversario: "Iniquitas partis adversae iusta bella ingerit gerenda sapienti" (Civ. Dei, XIX, 7).) Pero la guerra es un remedio muy extremo, pues trae consigo enormes males ("mala tam magna, tam horrenda, tam saeva") (Civ. Dei, XIX, 7). Y siempre el fin de la guerra ha de ser la paz y la justicia, el restablecimiento del orden: "Unde pacem constat esse optabilem finem" (Civ. Dei, XIX, 12). "Pax omnium rerum tranquillitas ordinis. Ordo est parium dispariumque rerum sua cuique loca tribuens dispositio" (Civ. Dei, XIX, 13). 
Santo Tomás, ${ }^{5}$ se tenía entonces para afrontar moralmente el problema de la guerra.

En los círculos intelectuales españoles del siglo XVI se vivió con gran intensidad el problema del decisivo título de guerra, debido a dos hechos fundamentales: de un lado, el descubrimiento y la conquista de América, asunto que planteaba el problema moral de la licitud de la conquista y de la guerra contra los indios; de otro lado, el rompimiento de la unidad de la Cristiandad europea por causa de la rebelión protestante, hecho que hacía muy difícil organizar un sistema de defensa colectiva, aflorando el peligro de la guerra internacional.

Vitoria piensa estas razones en tiempos de Carlos V (†1558); Molina y Suárez en los tiempos de Felipe II (†1598); y Suárez también en la época de Felipe III (†1621).

3. Francisco de Vitoria (1483-1546) afronta el asunto en su Relección De jure belli, explicada en la Universidad de Salamanca el 19 de junio de 1539.

En esa obrita se pregunta Vitoria, en primer lugar, si es lícito a los cristianos hacer la guerra. Coloca su contestación en un plano general, el del derecho natural, al que los cristianos también están sujetos. Se enfrenta así respectivamente al pacifismo de Erasmo ${ }^{6}$ y al belicismo de Maquiavelo. ${ }^{7}$ Responde, por tanto, que si hay verdadera causa o

5 Santo Tomás estableció cuatro condiciones fundamentales para que la guerra fuese moralmente justa (STh II-II q40 a1-a3).

Primera, autoridad soberana pública para declarar la guerra e iniciar las hostilidades, pues no basta la iniciación privada de las contiendas: "Primo, auctoritas principis, cujus mandato bellum est gerendum. Non enim pertinet ad personam privatam bellum movere: quia potest ius suum in judicio superioris prosequi. Similiter etiam quia convocare multitudinem, quod in bellis oportet fieri, non pertinet ad privatam personam".

Segunda, causa justa, o sea, que exista una culpa, un acto objetivamente injusto y jurídicamente imputable: "Secundo, requiritur causa justa: ut, scilicet, illi qui impugnantur propter aliquam culpam impugnationem mereantur".

Tercera, intención recta, colocando el bien común como razón y fin de la guerra: "Tertio requiritur ut sit intentio bellantium recta: qua, scilicet, intenditur vel ut bonum promoveatur, vel ut malum vitetur. Potest autem contingere quod, etiam si sit legitima auctoritas indicentis bellum et causa justa, nihilominus propter pravam intentionem bellum reddatur illicitum".

Cuarta, medios legítimos y proporcionados: "Nullus debet hostes fallere: sunt enim quaedam iura bellorum et foedera etiam inter ipsos hostes servando".

6 D. Erasmo (1466-1536), Opera, Leyde 1702-12: vol. II Adagiorum Collectanea (1536), p. 951-959; vol. IV Institutio Principis Christiani (1516), p. 608-610; vol. IV Quaerela Pacis (1517), p. 608.

7 N. Maquiavelo (1469-1527), Discursos sobre la primera década de Tito Livio (3 volúmenes, 1512-1517), lib. 1, cap. 26-29, lib. II, cap. 16-20; El Príncipe (1513), cap. 12, 13, 14, 26. 
motivación, la guerra puede ser hecha por el hombre, especialmente la guerra defensiva. También es lícita la guerra ofensiva si se ajusta a las exigencias del derecho natural. ${ }^{8}$

En cuanto a los títulos o motivos justos de guerra según la razón natural, Vitoria señala - como acabo de referir - que "la única causa justa para declarar la guerra es haber recibido injuria". ${ }^{9} \mathrm{Y}$ donde no hubo injuria violación del derecho - no debe haber venganza. Aunque, no cualquier injuria y de cualquier magnitud es suficiente para declarar la guerra: así, no lo es "la diversidad de religión", ni "el deseo de ensanchar el Imperio", ni lo es tampoco "la gloria del príncipe ni alguna otra ventaja para él". Esto último no, porque el príncipe debe ordenar lo mismo la guerra que la paz al bien común de su nación y no debe destinar las rentas públicas a su comodidad y a lustre suyo, y mucho menos puede exponer a sus súbditos a los peligros. Ahí está la diferencia entre un buen rey y un tirano. Además, como la autoridad del rey procede de la nación, él debe usarla para bien de la nación misma.

4. Mas para que la iniuria se convierta en "motivo suficiente" para hacer la guerra se han de observar algunas cautelas. ${ }^{10}$ La primera es que "no siempre justifica la guerra el que el príncipe crea que tiene motivo para ella"; pues antes es menester examinar con gran diligencia la justicia y las causas de ella y "oír también las razones de los contrarios, si de buen grado y con ánimo pacífico quieren entrar en negociaciones". Incluso al súbdito le incumbe parcialmente la obligación de ese examen, porque si a él le consta la injusticia de la guerra "no le es lícito pelear aunque lo mande el príncipe". Porque no es lícito matar al inocente por ninguna autoridad; y como en el caso de la injusticia de la guerra los enemigos

8 Porque la guerra defensiva sería ineficaz "si no se tomara venganza de los enemigos que injuriaron o intentaron injuriar, pues se harían éstos más audaces para acometer nuevamente, si no se les contuviese con el temor al castigo". Además, como el fin de la guerra es la paz y la seguridad de la república, "sería completamente inicua la condición de la guerra si, invadiendo injustamente los enemigos la república, sólo fuese lícito rechazarlos para que no pudieran proseguir su invasión". Considerando la licitud de la guerra bajo una consideración más general, es claro que "el mundo de ningún modo podría permanecer en un estado feliz, es más, la situación en todas las cosas sería pésima si tiranos, ladrones y raptores pudiesen impunemente cometer sus atropellos y oprimir a los buenos y a los inocentes, y, a su vez, si a la gente de orden no les fuera lícito prestarles ayuda" (F. de Vitoria, De Indis posterior sive De iure belli, ed. cit., n. 1).

9 FRANCISCO de Vitoria. De Indis prior, De titulis legitimis, n. 7: "Causa belli iusti est ad propulsandam et vindicandam iniuriam, ut supra dictum est ex Sancto Thoma II-II q40". También FRANCISCO Suárez, De Bello, sec, IV, n. 1: "Causa haec justa et sufficiens est gravis injuria illata, quae alia ratione vindicare aut reparari nequit".

10 FRANCISCO de Vitoria, De Indis posterior, sive De iure belli, n. 14, n. 20-22. 
son inocentes, no se les puede matar. Además, del súbdito hacia arriba, también los senadores y diputados "tienen obligación de examinar las causas de la guerra".

Pero si la guerra defensiva es dudosamente justa, entonces los súbditos tienen el deber de seguir a su príncipe; y lo mismo se diga si ese es el caso en la guerra ofensiva. Pues como en la duda ha de seguirse la parte más segura, si los súbditos no acompañan a su príncipe a la guerra, se exponen al peligro de entregar su patria a los enemigos. ${ }^{11}$

En cualquier caso, la declaración de guerra debe estar amparada por el juicio de justicia; y "si alguien hizo la guerra con probabilidad de que era injusta, tiene obligación, una vez adquirida certidumbre de la injusticia, de restituir lo quitado que no consumió".

5. En fin, si el juicio de justicia es correcto, en la guerra se permite lícitamente "todo aquello que requiere la defensa del bien público". Será, lícito también "recuperar todas las cosas perdidas y su precio", así como "resarcirse de los gastos de la guerra". ${ }^{12}$

Pero lo más importante en la guerra es la consecución de la paz. Por lo que es lícito que el príncipe que hace una guerra justa "pueda también hacer cuanto sea menester para asegurar la paz y tranquilidad del lado de los enemigos, a saber: destruir sus fortalezas y levantar defensas en tierra de ellos". Y eso porque lo primero que el príncipe debe procurar es "no buscar ocasión de pelear, sino vivir en paz con todos los hombres". De ahí la prohibición de la guerra de exterminio: si la guerra ha sido declarada con justa causa "no debe hacerse para exterminio del pueblo contra el cual se pelea, sino para lograr el fin de la guerra, la realización del derecho, la defensa de la patria, la paz y la seguridad". ${ }^{13}$

6. Y lo más difícil: que una vez lograda la victoria, el príncipe se transforme de guerrero en juez: "el vencedor se constituirá juez entre ambas partes, una la ofendida y la otra la que perpetró la injuria". El supuesto de esta insólita transformación (porque en principio nadie puede ser "juez" y "parte" en un mismo pleito humano) es el mismo que fundamenta una justa guerra; por eso no se da en el caso de una guerra injusta. Vitoria no admitiría la tesis más moderna de que en los vencedores, por ser tales, reside la razón y la justicia; o que el derecho está del lado del más fuerte. Por lo tanto esa transformación - del vencedor en juez - es un mandato de justicia "con el fin de que no como acusador, sino como juez pueda

11 FRANCISCO de Vitoria, De Indis posterior, sive De iure belli, n. 27.

12 FRANCISCO de Vitoria, De Indis posterior, sive De iure belli, n. 17-19.

13 FRANCISCO de Vitoria, De Indis posterior, sive De iure belli, n. 58-59. 
dictar sentencia con la que satisfaga a la parte perjudicada". Cuestión distinta es que esa metamorfosis psicológica o subjetiva se pueda lograr fácilmente. Ahora bien, Vitoria considera que tal transformación es un imperativo moral - en el sentido cuasi kantiano de la palabra -: para que nadie sea tratado como simple medio (instrumento), sino como fin en sí (persona). ${ }^{14}$

7. Pero con el logro de la victoria, con la recuperación de las propiedades y con la consecución de la paz y seguridad no acaba el cometido inicial de la guerra, que fue vengar la injuria, de modo que "es lícito vengar la injuria recibida y batir a los enemigos y castigarlos según la magnitud de sus delitos". Hasta el punto de que "es lícito matar a los rendidos que son culpables" y "si los prisioneros fueran culpables pueden ser ejecutados o entregados en guerra justa, guardando la debida equidad". Ahora bien, nunca es lícito matar directa e intencionadamente a los inocentes: porque el fundamento de la justicia de una guerra es la injuria, y es precisamente inocente el que no ha injuriado; luego no es lícito usar de la guerra contra él. ${ }^{15}$

8. En fin, en cuanto a saber quién tiene autoridad para hacer o declarar la guerra, Vitoria está convencido de que, en lo referente a la guerra defensiva, será todo aquel que sienta la violación de un derecho: "cualquiera, incluso una persona privada, puede emprender y hacer la guerra defensiva", aunque esa acción privada ha de ser puntual en el tiempo y en el espacio. En realidad, si es lícito rechazar la fuerza con la fuerza, consecuentemente "la guerra defensiva puede hacerla cualquiera sin autorización de nadie, no sólo para la defensa de la persona, sino también de las cosas y de los bienes". ${ }^{16}$ Con más razón - y ya en un plano político estricto - tiene autoridad para declarar y llevar a cabo la guerra "cualquier república". De modo que el soberano no tiene reservado para sí el derecho de hacer la guerra, pues "el soberano tiene la misma autoridad que la nación". De hecho, para Vitoria las repúblicas subordinadas y sus príncipes pueden de suyo declarar la guerra sin autoridad del príncipe superior: "porque una república debe bastarse a sí misma, y no se bastaría sin tal potestad".

Molina y Suárez, manteniendo básicamente los planteamientos y soluciones de Vitoria matizan dos puntos significativos: de un lado, sistematizan el contenido de los títulos de guerra y, de otro lado, rectifican

14 FRANCISCO de Vitoria, De Indis posterior, sive De iure belli, n. 60 .

15 FRANCISCO de Vitoria, De Indis posterior, sive De iure belli, n. 33-36.

16 FRANCISCO de Vitoria, De Indis posterior, sive De iure belli, n. 3. 
las competencias para declarar la guerra, las cuales recaen sólo en el Príncipe o Soberano, nunca en una persona privada. Ambas matizaciones tienen su justificación histórica en la estructuración psicológica y axiológica de la soberanía a finales del Siglo de Oro.

\section{El "honor" como título de guerra}

En aquella doctrina de Vitoria sobre la iniuria pronto se incluyeron motivaciones y grados. Porque la iniuria viene a ser un género que admite varias especies, que van desde la vulneración del derecho de propiedad, a la inobservancia del derecho al honor.

Así, por ejemplo Molina (1535-1600) afirma que hay al menos siete contenidos concretos envueltos en la iniuria: 1) La ocupación de aquello que se debe al Príncipe. 2) La rebelión injusta contra el Príncipe. 3) La injuria o contumelia notable contra el Príncipe o el Estado. 4) Prestar auxilio al enemigo que está en guerra injusta con el Príncipe. 5) Defender injustamente a algunos criminales, para evitar su justo castigo. 6) Que un Príncipe o Estado violen un tratado o pacto de gran interés. 7) Negar las cosas que por "derecho de gentes" están permitidas a todos. ${ }^{17}$

Como se puede apreciar, Molina destaca la ofensa pública notable (la contumelia, una ofensa al Príncipe o al Estado) como título suficiente para declarar la guerra. Pero acerca de esa concreta causa de guerra él no explica más en esta obra. Sí habla, en cambio, del honor vulnerado en la cuarta parte de su obra De iustitia et iure, parte dedicada precisamente al esclarecimiento del concepto de "honor".

2. A su vez, Suárez (1548-1617) se pregunta por los títulos que legitiman una guerra, y señala resumidamente tres especies de injurias que pueden mover a una guerra justa: $1^{\circ}$ Cuando un príncipe se apodera de las propiedades de otro (punto 1 de Molina). $2^{\circ}$ Cuando sin causa razonable niega los derechos comunes de gentes (punto 7 de Molina). $3^{\circ}$ Cuando hay una grave injuria en la reputación o el honor ${ }^{18}$ (punto 3 de Molina).

En cualquier caso, la ofensa al "honor" como título de guerra significa, en la España del Siglo de Oro, ${ }^{19}$ el desplazamiento de la contumelia intragrupal al deshonor supragrupal.

17 LUIS de Molina, De iustitia et iure (1593-1609), libro 11, Disputatio 104: De causis quibusdam particularibus iusti belli, scripturarum ejemplo roboratis, n. 1 .

18 SUÁREZ, De bello [1584], sec. IV, n. 3 (en Opus de triplici virtute theologica fide, spe \& charitate, Lugduni 1621).

19 Cfr. PIDAL. 1971. VALDECASAS. 1958. PERISTANY. 1968. PÉREZ Y LÓPEZ. 1786. GAUTHERON. 1992. WELCHMAN; HOSSAIN. 2005. RUIZ. 1969. BACKMANN. 1998. FEBVRE. 1996. ALVAREZ. 1981. 
3. La argumentación sobre injurias al honor como títulos de guerra se explica por el hecho de que el honor surge del profundo deseo humano de "reconocimiento", vigente y actuante en todas las épocas del mundo y en todos los seres humanos de todos los tiempos. Así lo había indicado ya Luis de Molina en su tratado De iustitia et iure, al definir el honor como "la manifestación [de algo] que se le hace a una persona en testimonio y reconocimiento de sus valores o de una excelencia suya". ${ }^{20}$

En realidad, desde que el hombre sale del seno materno siente la necesidad incoercible de ser reconocido por los otros como un sujeto con cierto valor positivo. Nadie anhela ser tratado como algo simplemente negativo, sin algún valor, siquiera el valor de la existencia misma. ${ }^{21}$

Aunque los filósofos de todos los tiempos han hablado de esa humana voluntad de reconocimiento, existen varios intentos modernos de sistematizar tal concepto. Así lo hizo Fichte en su obra sobre el "derecho natural". ${ }^{22}$ Teniendo en cuenta esta exposición fichteana hizo Hegel una briosa reconstrucción teórica ${ }^{23}$ en sus llamados "escritos de juventud", elaborados en Jena: en ellos se inicia un sistema especulativo en cuyo centro se encuentra el concepto de reconocimiento (Anerkennung). Bajo las pautas de aquel joven Hegel se despertó en Europa, tras la segunda guerra mundial (1945), un interés filosófico referido a la necesidad del reconocimiento para la formación de la autoconciencia, bajo la convicción de que nadie puede llegar por sí mismo a ese alto grado de desarrollo. Sólo en el encuentro mutuo de las conciencias se consigue lo que Hegel llama "movimiento de reconocimiento" (Bewegung der Anerkennung), "dialéctica del reconocimiento" (Dialektik der Anerkennung); movimiento y dialéctica que lleva en su base la "lucha por el reconocimiento" (Kampf um Anerkennung), en cuyo esfuerzo ve Hegel lo específico del

${ }^{20}$ LUIS de Molina. De iustitia et iure, Tractatus IV: De iustitia conmutativa circa bona honoris et famae, disput. 1, n. 1: "Honor est exhibitio alicui rei alicuius velut in testimonium ac recognitionem boni seu excellentiae illius".

21 Quizás por esta ley antropológica, en el orden estratégico de las empresas actuales el reconocimiento es una herramienta que trae consigo fuertes cambios positivos en la organización y en el rendimiento. En los varios estudios realizados sobre el reconocimiento al empleado se demuestra que en los lugares de trabajo más eficientes y eficaces existe una cultura de reconocimiento; esto es clave para el éxito de las empresas más competitivas, pues configura un conjunto de personas más comprometidas, productivas y fieles. El no dar reconocimiento trae sus consecuencias negativas.

Incluso el engaño psicológico que uno mismo puede sufrir "inventándose" ficticiamente la aprobación de los otros, sirve para que el sujeto sienta el gozo errático de estar en la existencia con algún tipo de valor. Pero mediante el efectivo reconocimiento que los otros me devuelven, crece en mí el sentimiento de mi propia existencia y de mi propio valor: empiezo a posibilitarme como hombre.

22 FICHTE. Grundlage des Naturrechts. Gabler, Jena und Leipzig, 1796.

23 WILDT. 1982. 
hombre. También en su Fenomenología del espíritu ${ }^{24}$ escribe Hegel un espléndido capítulo sobre el reconocimiento, bajo la dialéctica del señor y el esclavo (Herrschaft und Knechtschaft), para explicar la "sustantividad e insustantividad de la autoconciencia" (Selbständigkeit und Unselbständigkeit des Selbstbewusstsein). Sobre este análisis edificaría luego Karl Marx un modelo económico de lucha de clases; Jacques Lacan un modelo psicoanalítico; la Escuela de Frankfurt, un modelo de filosofía social, en la forma de una teoría crítica de la sociedad. ${ }^{25}$

Como es obvio, no es éste el lugar para entrar en la fronda de doctrinas actuales sobre el reconocimiento. Si he nombrado algunas es para llamar la atención sobre un hecho importante, a saber: que en el deseo de reconocimiento no sólo hay afirmación existencial, sino aprobación esencial de valores propios (recognitio boni et excellentiae, como decía Luis de Molina). Y es eso lo que se quiso expresar en el Siglo de Oro bajo el deseo de honor, cuya frustración pública en la figura del Príncipe, representante de un pueblo, sería causa suficiente para declarar la guerra al ofensor.

\section{Estructura psicosocial y moral del honor}

1. El deseo de honor no es un afán de sobresalir por encima de los demás, sino simplemente la voluntad de que los demás reconozcan al sujeto como depositario de valores que él mismo debe desplegar. Una buena descripción fenomenológica del honor está, dentro del mismo Siglo de Oro, en los dramas de honor de Lope y Calderón. ${ }^{26}$ Pero me limitaré a exponer brevemente el núcleo esencial del honor.

El honor tiene dos aspectos: de una parte, afecta al interior de nuestra personalidad; un agravio al honor es como una lesión a lo más propio e intransferible del individuo. El sonrojo en que se manifiesta la sensación del agraviado, se diría que trasluce una sangrante herida íntima. ${ }^{27}$

Pero, por otra parte, el honor viene de los otros: el honor nos aparece, a un tiempo, como exigencia interna y como consagración social, pues la honra consiste en el reconocimiento que otros me otorgan o tributan. De un lado, el honor es una dimensión íntima, un "patrimonio del alma". De otro lado, el honor tiene un aspecto externo, social. Así lo expresaba bellamente Lope: ${ }^{28}$

24 HEGEL. Phänomenologie des Geistes. Göbhard, Bamberg und Würzburg, 1807.

25 Cfr. HONNETH. 1992. BENHABIB. 2000. SIEP. 1975. SITZER; WIEZOREK. 2005.

26 BEYSTERVELDT. 1966. HONIG. 1972. CASTRO. 1961. LARSON. 1977. CHIABÒ; DOGLIO. 2003. WATSON. 1960. MARTINEZ. 1956. OOSTENDORP. 1962.

27 VALDECASAS. 1958, p. 119

${ }^{28}$ LOPE de Vega: Los comendadores de Córdoba, Acto III, Escena 11. 
Honra es aquella que consiste en otro.

Ningún hombre es honrado por sí mismo,

que del otro recibe la honra un hombre...
Ser virtuoso un hombre y tener méritos

no es ser honrado... De donde es cierto,

que la honra está en otro y no en él mismo,

Cuando la vida del individuo está entroncada en la vida de la comunidad, en orgánica compenetración, el sentirse repudiado por ella es como ser amputado del cuerpo y privado de la savia del propio ser.

2. Si el honor es el nexo de nuestra vida con la vida de la propia familia y de la ciudad en que se vive, o sea, si la vida individual sólo se estima valiosa en la propia comunidad, puede pensarse que el honor está realmente por sobre la vida propia. Y así se le estimó desde muy antiguo en España.

Honor, según las Partidas del Rey Sabio, es loor, reverencia o consideración que el hombre gana por su virtud o buenos hechos. Mas aunque la honra se gana con actos propios, depende de actos ajenos, de la estimación y fama que otorgan los demás. Así es que se pierde igualmente por actos ajenos, cuando cualquiera retira su consideración y respeto a otro: por eso, una bofetada, un mentís, deshonran si no se desagravian, y la deshonra es lo mismo que la muerte. Claramente dicen las Partidas: "el infamado, aunque no haya culpa, muerto es cuanto al bien y a la honra de este mundo". ${ }^{29}$

Por ejemplo, con la venganza - casi siempre un duelo de sangre - el hombre reparaba su honor, volvía a la vida, bajo los principios sociales en que su honor se fundaba. El ultraje al honor había de ser vengado.

En algunos dramas de capa y espada el deshonrado se muestra fiero, incluso sanguinario, invadido más por respetos sociales que por principios morales. Sin embargo, Lope indicaba: "el honor es patrimonio del alma, y el alma sólo de Dios".

3. Esto último lleva a pensar que en el mismo Siglo de Oro se vive un conflicto profundo entre la moral cristiana del perdón y las exigencias psicosociales, a veces homicidas, del honor.

${ }^{29}$ Partida $2^{\mathrm{a}}$, título 13 , ley $4^{\mathrm{a}}$; Partida $2^{\mathrm{a}}$, título 223. En esos textos se vincula la salvaguarda del "honor" a los justos títulos de guerra. E. Nys, "Les siete Partidas et le droit de la guerre" Rev. de Droit Internacional et Législastion Comparée, 15 (1883), p. 485. 
Bajo esta dialéctica - oposición entre las leyes de la moral que manda no matar, de un lado, y las leyes del honor que exigen venganza, de otro lado - se muestra la vigencia social del honor.

Lo primero que moralmente se entiende entonces de la esencia del honor es que tiene su fundamento en la virtud; y esta es su más íntima esencia, a pesar de su discrepancia con la mera vigencia social.

a) En tal sentido, el honor que está basado en la virtud expresa la nobleza del hombre. De manera que donde no hay virtud no podrá haber nobleza.

b) La mera ascendencia noble no arguye nobleza, sino obligación de ser noble, y, a lo más, un crédito de confianza: se espera un noble comportamiento de quien tal ascendiente tiene.

c) En realidad, la virtud se prueba por las obras, como por los frutos se conoce el árbol. Por consiguiente, cada cual es hijo de sus obras. Así lo reconoce Don Quijote, dirigiéndose a Sancho: "Repara, hermano Sancho, que nadie es más que otro, si no hace más que otro".

d) Pero las obras en cuestión consisten más en la acción esforzada que en el resultado o el éxito. Quizás por este argumento, Cervantes proclamó la falta de nobleza y honor que hay en dejarse seducir por el éxito, en ponerse - sin más motivo - de parte del vencedor. Exclama Don Quijote contra su Escudero: "Bien parece, Sancho, que eres villano, y de aquellos que dicen iViva quien vence!". Hasta cierto punto son opuestos el honor y el éxito.

e) El honor hispánico es animoso y valiente, hasta fanfarrón a veces, pero puesto al servicio de lo cristiano. El honor está inmediatamente unido a la virtud y al ideal religioso, en su sentido más elevado.

f) El honor intragrupal sólo cede ante el rey. En el Siglo de Oro, todos los móviles humanos debían subordinarse al honor personal y social, pero ese honor sólo cedía ante la persona del rey. Este fenómeno fue advertido por Santo Tomás de Aquino, quien expone una objeción según la cual en el honor se muestra reverencia en testimonio de virtud; pero ocurre que a veces hay superiores que no son virtuosos; por tanto, no se les debería honrar. A esta objeción contesta el Aquinate que los superiores no se honran por su virtud propia: lo que se honra realmente es la excelencia de su dignidad; lo que se honra en ellos es a la comunidad íntegra, tota communitas. ${ }^{30}$

Esta subordinación de la dignidad individual al bien común expresa terminantemente el carácter social del sentimiento del honor.

30 TOMAS de Aquino. S.Th., II-II q103, a 2: "Si praelati sunt mali, non honorantur propter excellentiam propriae virtutis, sed propter excellentiam dignitatis, secundum quam sunt dei ministri. Et in eis etiam honoratur tota communitas, cui praesunt". 
La dialéctica entre las vigencias sociales y la virtud que ocurre en el ámbito familiar y conyugal, es la misma dialéctica que, en el plano más elevado de la patria, comparece en la propuesta de Suárez - vigente en el Siglo de Oro - sobre el derecho a la guerra motivada por una injuria al honor de la Nación y del Soberano.

\section{El honor de la nación y del soberano}

a) El nacimiento de la "opinión pública"

1. La tesis de Suárez sobre "la injuria al honor" de la nación y del soberano como título de guerra, se halla, como dije, en la disertación XIII Sobre la caridad. En otra obra dice Suárez: "La infamia es la disminución injusta de un estado de reconocimiento, hecha sobre alguien por la opinión pública injusta". ${ }^{31} \mathrm{El}$ honor patrio, en este caso, es afectado por la injuria.

En este momento la injuria intragrupal al honor se desplaza a la injuria supragrupal. Esto es así porque en el siglo XVI ha cobrado fuerza una nueva noción, un nuevo modo de encarar los asuntos políticos: ha nacido la opinión pública, un concepto decididamente moderno.

Quien desee conocer la vivencia que un español del Siglo de Oro tiene ante la planetización de España, oiga la exhortación que el jesuita Pedro de Ribadeneira (1527-1611) escribió para los soldados de la Armada Invencible, apelando nada menos que a la opinión pública:

El mundo se gobierna por la opinión, y más las cosas de guerra; con ella se sustentan los imperios mientras ella está en pie, ellos están; y cayendo ella, caen; y con la reputación muchas veces se acaban más cosas que con las armas y con los ejércitos. Y los Reyes y Príncipes poderosos de ninguna cosa deben ser más celosos después de hacer lo que deben a Dios y a sus reinos, en ninguna más vigilantes y solícitos, que en ganar, conservar y acrecentar esta opinión, y que todo el mundo sepa, que ni ellos quieren hacer agravios, ni consentir que nadie se los haga a ellos. Porque perdiéndose esta reputación se pierde mucho; y una vez perdida, con dificultad se vuelve a recobrar. Todo el mundo teme nuestro poder, y aborrece nuestra grandeza; tenemos muchos enemigos descubiertos y muchos más encubiertos y amigos fingidos; los descubiertos, faltando la reputación, tomarán ánimos para acometernos, y los encubiertos para descubrirse y publicar lo que tienen encerrado en sus pechos. ${ }^{32}$

Ribadeneira afirma que todo estaría perdido si "se perdiese la reputación con que los reinos se sustentan". ${ }^{33}$

31 Suárez, De censuris, d48 sc.1. n. 1

32 DE RIBADENEIRA, P. Exhortación para los soldados y capitanes que van a esta jornada de Inglaterra, en nombre de su capitán general, Apéndice I, publicado en el Tratado de la tribulación [1589], Salamanca 1988, p. 440-1.

33 DE RIBADENEIRA, P. op. cit., p. 441. 
2. El honor es ahora una relación social entre Estados. Y un pueblo no puede quedar impasible ante el honor ultrajado. ${ }^{34} \mathrm{El}$ honor es el valor irrenunciable no sólo de la persona física, sino también de esa persona moral que es el Estado. "El catedrático de Coimbra ha elevado esa tesis a derecho público como título de guerra justa, fórmula viva en la conciencia nacional del pueblo. Ante el honor, los demás bienes naturales no tienen importancia; y lo que no puede evitarse sin gran infamia y deshonra moralmente es inevitable, porque todos los Estados tienen derecho a su fama". 35

Suárez analiza el concepto y formas de honor en su libro Sobre las censuras eclesiásticas y el Tratado sobre las leyes.

El prestigio de que goza un Estado en la comunidad de pueblos por sus actos y dignidad personal, constituye la fama. La opinión pública es su elemento esencial. El derecho a este estado de opinión pública positiva es exigido por el honor. ${ }^{36}$

Incluso el tratamiento del vencido es distinto cuando la injuria infligida es la realizada por "ocupación indebida" y no por "ofensa al honor". Así, en el cuadro de Velázquez llamado de "Las lanzas" o "La rendición de Breda" se expresa el final de una guerra que se ha producido esgrimiendo uno de los títulos de guerra, el de propiedad, pero no el título del honor. Por lo tanto, tanto el general rendido (Nassau) como el general victorioso (Spínola) tienen a salvo su honor. Se llegó a una capitulación honrosa que el ejército español reconoció como tal, admirando en su enemigo la valentía de los asediados en Breda. ${ }^{37}$ Por esta razón permitió que la guarnición saliera formada en orden militar, con sus banderas al frente, como se puede comprobar en el cuadro. Los vencidos fueron respetados y tratados con dignidad. En el cuadro no hay vanagloria. Justino de Nassau aparece con las llaves de Breda en la mano y hace ademán de arrodillarse, lo cual es impedido por Spínola que pone una mano sobre su hombro y le impide humillarse.

"Todos tienen derecho a que su prestigio internacional se respete, porque es necesario para la convivencia social. El atentado, pues, contra esta reputación nacional es la mayor injuria que se puede inferir a la persona. Cuando a un pueblo se le difama o se le calumnia y pierde su prestigio en la opinión pública; cuando se le desprecia, posterga o

34 Véanse estas ideas muy bien argumentadas en la obra de PEREÑA. 1954, p. 147-8.

35 PEREÑA. op. cit., p. 149.

36 PEREÑA. op. cit., p. 149.

37 Para más detalles y posibles interpretaciones de este famoso cuadro, cfr. FIOL. 1979; con oportuna bibliografía. 
se le pospone a Estados menos dignos, se dice que su honor ha sido ultrajado". ${ }^{38}$

3. La exposición que acabo de hacer se atiene a un ambiente, a una conciencia nacional, a una dimensión hispánica. Si el honor era la más grande ofensa que podía recibir el hidalgo del siglo XVI, ${ }^{39}$ también la mancha en la dignidad de la Patria puede ser vengada con las armas, dice Suárez.

Este honor nacional estaba tan exaltado en el español del siglo XVI, que el Nuncio de Roma en Madrid afirmaba en su instrucción de 1581 que por ello eran odiados los españoles en el extranjero. ${ }^{40}$

Así, el tratado sobre la guerra en Francisco Suárez es la justificación de la hazaña española en defensa del honor.

b) La justificación de la política española en defensa del honor

1. Por encima de la institución de la Nación está, para un español del siglo XVI, la Iglesia católica.

Ahora bien, pensemos que por entonces el Papa era, de un lado, un Príncipe político, gobernando un Estado con amplios territorios propios; de otro lado, también era el Príncipe espiritual de la Cristiandad. Lo político y lo espiritual eran vividos a veces como indiscernibles. En el mundo europeo, toda actuación de Roma quedaba con frecuencia cargada de equívocos.

En lo que a la Península Ibérica se refiere, a la muerte de los Reyes Católicos España se convierte en el bastión europeo de la Catolicidad, incluso en su intérprete auténtico. España no tolera que ningún príncipe europeo pueda llamarse católico por excelencia; y si alguna vez Roma se dirige a un príncipe europeo para pedirle ayuda, España protesta airadamente. De hecho, la política de Carlos V fue un duelo sangriento con Francisco I de Francia, desoyendo las voces de Roma. ${ }^{41}$ Incluso un duelo contra Roma, como se demuestra en el saqueo que hicieron en la Ciudad Eterna las tropas del Emperador.

Después, la política de Felipe II se centró contra la Inglaterra creada por el cisma. Se veía en Inglaterra el mayor enemigo de la cristiandad y, por lo tanto, de España; pero en ese orden. Felipe II estaba íntimamente convencido de que sólo la religión puede conservar la unidad y la paz. Sólo en el catolicismo podía establecerse la unidad de Europa. Por eso

38 PEREÑA. op. cit., p. 149.

39 PEREÑA. op. cit., p. 149.

40 PEREÑA. op. cit., p. 150.

41 PEREÑA. op. cit., p. 66-7. 
se erige en el salvador de la cristiandad, el brazo derecho de la iglesia, el hombre providencial contra los enemigos que venían de la Europa atea. Acaba creyendo que la Cristiandad era el Estado Español. ${ }^{42}$

Esa identificación es decisiva en aquella política de Felipe II. La guerra se hace por razón de Estado cristianizado. El triunfo de la catolicidad es también el triunfo de España. El catolicismo para el español del siglo XVI estaba confinado al territorio de España o a sus aliados unidos por lazos de dinastía. Hasta Francia era la enemiga peligrosa del Cristianismo. Felipe se creía, él sólo, el brazo del Omnipotente.

Felipe II ejerció una verdadera jurisdicción sobre la influencia de Roma en España: prohibía bulas y breves que desatendieran los altos intereses del Estado. Todo atentado contra la Monarquía era un ataque contra la misma Fe. ${ }^{43}$

España luchaba por la cristiandad, pero interpretada sólo por los teólogos españoles. Si dogmáticamente, espiritualmente, dependía de Roma, disciplinariamente el clero se sentía más dependiente de la Corte de Madrid que de la curia pontificia. ${ }^{44}$

Por eso, Roma mantuvo una firme política de acercamiento a España, cuya época más amistosa fue la de Felipe III, el Rey Piadoso, quien dio un giro notable a la política española: bajo su reinado la Monarquía Hispánica alcanzó su mayor hegemonía imperial y su mayor expansión territorial, consecuencia denominada como Pax Hispánica.

2. En aras del honor nacional se exigía el sacrificio de todos los valores materiales y aun espirituales.

Suárez, en su teoría de guerra, ha sentado el principio justificante de esta política que debía salvar el honor, aunque tuviera que arruinar la existencia de los súbditos. ${ }^{45}$ Los que atentan, auxilian, favorecen, cooperan a la injuria supragrupal, pueden ser vengados por las armas.

A nadie se le oculta el peligro que supone este concepto en la teoría de la guerra. Por varias razones: primero, porque un monarca podrá explotar siempre la causa de su honor ultrajado, de su reputación calumniada. Segundo, porque ese concepto puede llevar a una depravación humanitaria: un pueblo puede ser fanatizado por los resortes de la propaganda; es posible crear una excitación nacional y llegar hasta el convencimiento sincero de que peligra el honor del Estado. Tercero, porque las masas dominadas por minorías demagógicas pueden ser

42 PEREÑA. op. cit., p. 68-70.

43 PEREÑA. op. cit., p. 70-2.

44 PEREÑA. op. cit., p. 72-5.

45 PEREÑA. op. cit., p. 152. 
arrastradas a nacionalismos histéricos, dispuestos siempre a crear nuevas causas de guerra. ${ }^{46}$

3. Pero la injuria al honor como título de guerra sufre con Suárez una segunda vuelta de tuerca, dirigiéndola no ya al honor del Estado, sino al honor del Soberano mismo. ${ }^{47}$

De modo que al final podría resultar que el honor de la nación es sobre todo el honor del Soberano. Primero, porque el soberano es persona pública y la encarnación del Estado; ya que es cabeza del cuerpo político. Segundo, porque por su dignidad, la vida del Soberano es preferible a todos los bienes externos y de fortuna. Tercero, porque el Soberano representa a Dios de un modo especial. Cuarto, porque el Soberano tiene cierta administración suprema sobre todos los bienes y aun la vida de sus súbditos; puede, pues, exponerlos a peligro grave de su vida y hacienda, porque la vida de los ciudadanos pertenece más al Estado que a ellos mismos; pero sólo en cuanto es necesario para el bien general.

El deslizamiento del honor del Estado al honor del Soberano estuvo presente en la vida y en la filosofía política española.

Pero esta segunda vuelta de tuerca en materia de honor público, abre en realidad las puertas a una consagración práctica del bien particular del Soberano. El Rey podría obligar a una guerra para defender sus derechos personales; exponer el bien de uno de sus Estados para lograr, por ejemplo, el derecho a la sucesión a otro Reino, cosa que ocurrió con Felipe II en el caso de la anexión de Portugal a la corona Española. ${ }^{48}$

4. Pues bien, de esos posibles abusos habían avisado ya grandes maestros de la Escuela de Salamanca; Vitoria los desenmascara en su relección De Indis prior; y Suárez también los denuncia en varias obras.

Ambos vienen a decir que cuando un soberano oprime injustamente a su pueblo ha perdido la justificación de su poder, no existe ya una autoridad injusta, sino que la misma potestad ha dejado de existir, se ha convertido en tirano. Ya no hay honor en el pueblo. Y ante la tiranía todo pueblo tiene derecho a rebelarse, a recobrar su honor. El derecho a la rebeldía es una limitación política a los intentos belicistas privados del Soberano. Cuando es clara la motivación política basada en el bien privado del Soberano, los súbditos tienen derecho a pedir ayuda a otros Estados para que sancionen con la guerra toda opresión injusta. ${ }^{49}$

\footnotetext{
46 PEREÑA. op. cit., p. 153.

47 FRANCISCO Suárez, De Legibus, lib. 1, cap. 7; lib. V, cap. 15; Defensio Fidei, lib. VI, cap. 4.

48 PEREÑA. op. cit., p. 76-106.

49 FRANCISCO Suárez, De Bello, sec. VIII; Defensio Fidei, lib. VI, cap. 4.
} 
Tiranía es un asalto injusto al poder, hecho por un Soberano: se trata del ejercicio egoísta de un poder que sacrifica el bien común por el privado y condena a un pueblo a la opresión en aras del interés personal. Sólo en el bien común se salva el honor de un pueblo. Así lo había subrayado Luis de Molina un poco antes que Suárez, con una fuerza inusitada: "Si un rey quiere asumir facultades que no le han sido concedidas, podrá la república resistirle como a tirano en cuanto a esa parte usurpada de su poder, del mismo modo que podría oponerse a un extraño que intentase causarle injuria". ${ }^{50}$ Esta conclusión tiene su fundamento en una tesis previa: "Creado un rey, no por eso se ha de negar que subsisten dos potestades, una en el rey, otra cuasi-habitual en la república, impedida en su ejercicio (impeditam in actu) mientras dura aquella otra potestad, pero sólo impedida en cuanto a las precisas facultades que la república obrando independientemente encomendó al monarca. Abolido el poder real, puede la república usar íntegramente de su potestad. Más aún, permaneciendo aquél podrá resistirle si comete alguna injusticia contra la misma o rebasa las atribuciones políticas que le fueron concedidas. Puede también la república ejercer inmediatamente por sí todas las facultades cuyo uso se haya reservado". ${ }^{51}$

En la misma línea Suárez argumenta que "ninguna potestad política procede inmediatamente de Dios (nullus principatus politicus est immediate a Deo); y que, por tanto, según el orden natural de las cosas, ningún rey o monarca tiene ni ha tenido inmediatamente de Dios el principado político, sino mediante la voluntad y la institución humanas (sed mediante humana voluntate et institutione)".

5. Es, por tanto, la misma doctrina que, en la primera mitad del siglo XVI, distinguía en un mismo pueblo estructurado políticamente la potestad radical y la potestad actual, o entre la potestad constituyente y la potestad constituida.

Así se expresó mucho antes Martín de Azpilcueta (el Doctor Navarro), estableciendo una diferencia entre conceder el poder y transferirlo: pues el poder permanece siempre radicalmente en el pueblo, aunque en acto sea ejercido por un soberano: "No obsta que muchos pueblos carezcan aparentemente de toda jurisdicción, porque en rigor no carecen de ella, sino de su ejercicio. La conservan por lo menos in habitu, aunque no la posean in actu. Y por eso cuando llegue el caso de que no se provea debidamente al gobierno de los pueblos por aquellos a quienes mediante elección, herencia, o de otro modo, se haya concedido el ejercicio de la

50 LUIS de Molina, De Iustitia et Iure. I, Cuenca, 1593, col. 176-178.

51 LUIS de Molina, De Iustitia et Iure. I, Cuenca, 1593, col. 189. 
jurisdicción, podrán usarla". Y en otro texto: "La sociedad civil, aunque concedió a emperadores y reyes el uso y ejercicio de la jurisdicción, que a ella naturalmente pertenecía, retuvo el hábito y la raíz de la misma, pudiendo por lo tanto volver las cosas, aun en cuanto al uso de la jurisdicción, al estado primitivo [...]. Los reinos no sólo son anteriores a los reyes, sino también superiores a ellos, en aquellos casos en que los monarcas abusen de la potestad que se les concedió empleándola en la destrucción de sus propios estados o dirigiéndola a fin contrario de aquel para el que los pueblos se la concedieron o debieron concedérsela". ${ }^{52}$

En el mismo sentido se expresó Francisco de Vitoria: "Por disposición divina tiene la república esta potestad, pero la causa material en que reside, según el derecho natural y divino, es la misma república a la cual de suyo pertenece regirse y administrarse dirigiendo todas sus facultades al bien común. Pruébase de esta manera: Por derecho natural y divino existe la potestad de gobernar la república; y, como si se prescinde del derecho positivo y humano, no hay razón alguna para que este poder resida en una persona con preferencia a otra, necesario es que la misma comunidad se baste para dicho fin y posea la facultad de regirse a sí propia [...]. Pues la República es la que crea al rey (creat enim respublica regem)". ${ }^{53}$ Idéntica doctrina encontramos en Domingo de Soto (14951560): "Los reyes y monarcas seculares no han sido creados próxima e inmediatamente por Dios [...], sino que los reyes y príncipes han sido creados por el pueblo, que les transfirió su imperio y potestad [...] "Por consiguiente, aquello de: 'por mí reinan los príncipes', etc. no se ha de entender en otro sentido sino en el de que Dios, como autor del derecho natural, ha concedido a los mortales que cada república tenga la facultad de regirse a sí misma y, en consecuencia, la de que, si lo aconseja la razón, que es también como un destello de la divina luz, pueda transmitir esa potestad a otro, por cuyas leyes se gobierne más expeditamente". ${ }^{54}$ Y en Diego de Covarrubias y Leyva (1512-1577): "La potestad temporal y la jurisdicción civil, íntegra y suprema, reside en la república. Por lo

52 MARTín de Azpilcueta (1493-1586), Relectio cap Novit de Iudiciis [1548], (Martini Azpilcuetae Navarri, Opera omnia in sex tomos distincta. T. IV, Venetus, apud Iuntas, 1602, p. 592-595). Y también: "La potestad es dada por Dios, naturalmente, de modo inmediato a la comunidad de los mortales para que vivan bien y dichosamente, conforme a la razón natural" ( $I b, \mathrm{p}$. 588). "El reino no es del rey, sino de la comunidad, y la misma potestad regia no pertenece por derecho natural al rey, sino a la comunidad, la cual, por lo tanto, no puede enteramente desprenderse de ella" (Ib., p. 592).

53 Relectiones Theologicae XII in duos tomos divisae, Lugduni, 1557; De Potestate Civili, n. 7.

54 DOMINGO de Soto, De Justitia et Jure libri decem, q. 1, a. 3. Salmanticae, Andreas a Portonariis 1553. 
tanto, sólo podrá regirla como príncipe temporal, a todos superior, aquel que haya sido elegido y constituido por la república misma. Así procede según el derecho natural y de gentes [...]. El jefe supremo de la sociedad y república civil sólo pude ser constituido justamente y sin incurrir en tiranía por la misma república". ${ }^{55}$

Podrían multiplicarse testimonios que acreditan la unidad de criterio que, sobre la constitución del "poder" para hacer la guerra, había entre los intelectuales españoles más destacados. Pero son suficientes los aducidos para comprender que cuando es difícil trazar una raya de separación entre el interés del Soberano y el interés del Pueblo - los hombres que hacen la comunidad, depositarios inmediatos del poder no puede haber duda de que, en su sentido público, el honor se le debe siempre al Pueblo.

Un Estado, una Nación - un Pueblo - tiene el derecho de que se respeten sus instituciones, sus leyes y costumbres como parte integrante de su propia vida; el derecho a defender su religión verdadera, sus tesoros, sus bienes comerciales, culturales y artísticos que forman el patrimonio nacional. Por lo tanto, la causa suprema a que, en este caso, debe subordinarse el poder de la guerra es el honor nacional.

\section{Referencias}

AGUSTÍN. Contra Faustum, ML, 42.

. De libero arbítrio, ML, 32

. Quaestiones in Hept., ML, 34.

. De Civitate Dei, ML, 41.

ALVAREZ, F. J. G. Honor y honra en la España del siglo XVIII. Madrid: Universidad Complutense, Departamento de Historia Moderna, 1981.

BACKMANN, S. (Ed). Ehrkonzepte in der Frühen Neuzeit: Identitäten und Abgrenzungen. Berlin: Akademie-Verlag, 1998.

BENHABIB, S. Kulturelle Vielfalt und demokratische Gleichheit. Politische Partizipation im Zeitalter der Globalisierung. Frankfurt am Main: Fischer, 2000.

BEYSTERVELDT, A. Répercussions du souci de la pureté de sang sur la conception de l'honneur dans la "comedia nueva" espagnole. Leiden: Brill, 1966.

CASTRO, A. De la edad conflictiva. Vol. I: El drama de la honra en España y en su literatura. Madrid: Taurus, 1961.

CHIABÒ, M.; DOGLIO, F. (Ed.). Tragedie dell'onore nell'Europa barocca. Centro studi sul teatro medioevale e rinascimentale. Roma: Torre d'Orfeo, 2003.

55 DIEGO de Covarrubias y Leyva. Didaci Covarruvvias a Leyva, Toletani, episcopi segobiensis, Philippi Secundi, Hispaniarum regis, summo praefecti praetorio Opera Omnia, Lugduni, 1574, Tomas Secundus (Practicarum Quaestionum), libro primero, p. 416, col. $1^{\mathrm{a}}$. 
DE RIBADENEIRA, P. Exhortación para los soldados y capitanes que van a esta jornada de Inglaterra, en nombre de su capitán general, Apéndice I, publicado en el Tratado de la tribulación [1589], Salamanca: 1988, p. 440-1.

DIEGO de Covarrubias y Leyva. Didaci Covarruvvias a Leyva, Toletani, episcopi segobiensis, Philippi Secundi, Hispaniarum regis, summo praefecti praetorio Opera Omnia, Lugduni, 1574, Tomas Secundus (Practicarum Quaestionum).

DOMINGO de Soto. De Justitia et Jure libri decem. Salmanticae: Andreas a Portonariis, 1553.

ERASMO. Opera. Leyde, 1702-12

FEBVRE, L. Honneur et patrie. Paris: Perrin, 1996.

FICHTE. Grundlage des Naturrechts. Gabler, Jena und Leipzig, 1796.

FIOL, B. M. “Felipe IV en 'La rendición de Breda', de Velázquez". Boletín de la Real Academia de Bellas Artes de San Fernando, 49 (1979), p. 173-215

FRANCISCO de Vitoria. De Indis posterior, sive De iure belli. In: Relectiones. Salmanticae apud Ioannem a Canoua, 1565, tomo I.

Relectiones Theologicae XII in duos tomos divisae, Lugduni, 1557 . De Potestate Civili.

$\overline{\text { tomo I. }}$

. De Indis prior. In: Relectiones. Salmanticae apud Ioannem a Canoua, 1565,

FRANCISCO Suárez. De Bello. In: Opus de triplici virtute theologica fide, spe \& charitate, Lugduni 1621.

Lugduni 1621.

. De Legibus. In: Opus de triplici virtute theologica fide, spe \& charitate, . Defensio Fidei. In: Opus de triplici virtute theologica fide, spe \& charitate, Lugduni 1621.

GAUTHERON, M. (ed.). El honor: imagen de sí mismo o don de sí, un ideal equívoco. Madrid:Cátedra, 1992.

HEGEL. Phänomenologie des Geistes. Göbhard, Bamberg und Würzburg, 1807.

HONIG, E. Calderón and the seizures of honor. Cambridge: Harvard University Press, 1972.

HONNETH, A. Kampf um Anerkennung. Zur moralischen Grammatik sozialer Konflikte. Frankfurt am Main: Suhrkamp, 1992.

KAGAN, D. Sobre las causas de la guerra y la preservación de la paz. Madrid: Turner \& Fondo de Cultura Económica, 2003.

LARSON, D. R. The honor plays of Lope de Vega. Cambridge: Harvard University Press, 1977.

LOPE de Vega: Los comendadores de Córdoba, Acto III, Escena 11.

LUIS de Molina, De iustitia et iure. Cuenca: 1593-1609.

MAQUIAVELO, N. Discursos sobre la primera década de Tito Livio (3 volúmenes, 1512-1517). . El Príncipe (1513). 
MARTÍNEZ, E-I. S. "Honneur" y "Honor", su significación a través de las literaturas francesa y española (Desde los orígenes hasta el siglo XVI). Murcia: Universidad, 1956.

OOSTENDORP, H. TH. El conflicto entre el honor y el amor en la literatura española hasta el siglo XVII. La Haya: Van Goor Zonen, 1962.

MARTÍN de Azpilcueta. Relectio cap Novit de Iudiciis [1548]. In: Martini Azpilcuetae Navarri, Opera omnia in sex tomos distincta. T. IV, Venetus, apud Iuntas, 1602.

PEREÑA, L. Teoría de la guerra en Francisco Suárez, v. I: Guerra y Estado. Madrid: C.S.I.C., Instituto Francisco de Vitoria, 1954.

PÉREZ Y LÓPEZ, A. X. Discurso sobre la honra y deshonra legal: en que se manifiesta el verdadero mérito de la nobleza de sangre. Madrid: Imprenta Real, 1786.

PERISTANY, J. G. El concepto del honor en la sociedad mediterránea. Barcelona: Labor, 1968.

PIDAL, R. M. Del honor en el teatro español [Conferencia de 1937]. Barcelona: Almacenes Generales de Papel, 1971.

RUIZ, R. S. Honor, honra e injuria en el derecho medieval español. Murcia: Sucesores de Nogués, 1969.

SIEP, L. Anerkennung als Prinzip der praktischen Philosophie: Untersuchungen zu Hegels Jenaer Philosophie des Geistes. Freiburg: 1975.

SITZER P.; WIEZOREK, C. "Anerkennung". In: HEITMEYER, W.; IMBUSCH, P. (Hrsg.): Integrationspotenziale einer modernen Gesellschaft. Wiesbaden: VS-Verlag, 2005, p. 101-32.

TOMÁS de Aquino. Summa Theologiae. In: www.corpusthomisticum.org

VALDECASAS, A. G. El hidalgo y el honor. Madrid: Revista de Occidente, 1958.

WATSON, C. B. Shakespeare and the Renaissance concept of honor. Westport: Greenwood Press, 1960.

WELCHMAN, L.; HOSSAIN, S. "Honour": crimes, paradigms, and violence against women. London; New York: Zed Books, 2005.

WILDT, A. Autonomie und Anerkennung: Hegels Moralitätskritik im Lichte seiner Fichte-Rezeption. Stuttgart: Klett-Cotta, 1982. 